Article

\title{
Direct Synthesis of Adsorbent Having Phosphoric Acid with Radiation Induced Graftpolymerization
}

\author{
Fatmuanis BASUKI, \\ Center for Education and Training, National Nuclear Energy Agency, JL. Raya Pasar Jumat PO BOX 1810 JKS, \\ Jakarta 12018, Indonesia, \\ Noriaki SEKO, Masao TAMADA, Takanobu SUGO and Tamikazu KUME \\ Takasaki Radiation Chemistry Research Establishment, Japan Atomic Energy Research Institute, 1233 Watanuki, \\ Takasaki, Gunma 370-1292, Japan,
}

(Manuscript submitted January 27, 2003; accepted April 5, 2003)

\begin{abstract}
Radiation induced graftpolymerization is a sophisticated tool for introducing the aiming functional group into the conventional polymer. Adsorbent having phosphoric acid was directly synthesized by grafting methacrylate monomer having phosphoric acid onto polyethylene nonwoven fabric. Degree of grafting $\left(D_{g}\right)$, which was estimated by increment weight after grafting, reached $185 \%$ when the $10 \%$ monomer in the mixture of $10 \%$ methanol and $90 \%$ water was reacted with $200 \mathrm{kGy}$-irradiated nonwoven fabric. The adsorbent of $160 \% D_{g}$ revealed that adsorption capacity was $3 \mathrm{mmol} / \mathrm{g}$-adsorbent for $\mathrm{Pb}$ and $\mathrm{Cd}$ ions in column mode. The removal of these metals could be performed with space velocity of $250 \mathrm{~h}^{-1}$.
\end{abstract}

\section{Introduction}

Removal of toxic metal from the industrial waste water and mine water is important to preserve clean environment. A chelate adsorbent has been researched extensively since this is a promising material to remove such toxic metal ions effectively. On the point of view of adsorbent synthesis, radiation-induced graftpolymerization is an excellent method to introduce the chelate function into variety shapes of conventional polymers such as fiber, membrane, particle, and hollow fiber. Especially, fibrous adsorbent prepared by this method realized 100 times higher space velocity than that of commercialized particle-adsorbent in the removal column of the toxic metals.[1] Such chelate adsorbent is synthesized by grafting the precursor monomer and the following chemical reaction. In the case of phosphoric acid adsorbent having high selectivity to hard Lewis acids cations, [2] the monomer having the functional group of epoxy[3] was grafted on the trunk polymer at first and then the resulting material was phosphorylated by chemical reagents. The direct synthesis of phosphoric acid adsorbent was attempted by chemical grafting. However, enough high grafting yield for adsorbent was not obtained.[4] The present paper dealt with the direct synthesis of phosphoric acid adsorbent by radiation-induced graft polymerization and the evaluation of the obtained adsorbent for the removal of toxic metals. In the direct synthesis of adsorbent, the production process is quite simplified and the density of functional group can be controlled only by condition of grafting reaction. These points will become big merit in the industrial production of the adsorbent. 


\section{Experimental}

\subsection{Materials}

A phosphoric acid monomer (2-hydroxyethyl methacrylate phosphoric acid (HMPA); Kyoeisha Co. Osaka, Japan,) was used for grafting monomer which was composed of the mixture of mono (50\%) and diester (50\%) as shown in Fig. 1. Nonwoven fabric composed of polyethylene-coated polypropylene fiber (Fig. 2; Kurashiki Textile MFG Co. Ltd., Osaka, Japan) was used as a trunk polymer.

\subsection{Radiation induced graftpolymerization}

The nonwoven fabrics were cut into the rectangle of $3 \mathrm{~cm} \times 5 \mathrm{~cm}$ and were irradiated with electron beam up to $200 \mathrm{kGy}$ in nitrogen gas. Then, the methanol-water (10/90 wt\%) solution of HMPA was contacted with these irradiated nonwoven fabrics in a deaerated glass reactor. The reaction temperature was maintained by dipping the glass reactors into a warm bath. After the grafting reaction, the degree of grafting $\left(D_{g}\right)$ was calculated by the following equation:

$$
D_{g}[\%]=\left(W_{g}-W_{o}\right) \times 100 / W_{o}
$$

where $W_{0}$ and $W_{g}$ are the weights of nonwoven fabrics before and after graftpolymerization, respectively.

\subsection{Metal adsorption}

In the batch adsorption, the adsorbent of $150 \% D_{g}$ was cut into the squares of $1 \mathrm{~cm} \times 1 \mathrm{~cm}$ (approximately $0.01 \mathrm{~g}$ ). The square adsorbent was soaked in the $50 \mathrm{ml}$ of $10 \mathrm{ppm}$ metal solution for $48 \mathrm{~h}$. The metal solutions were obtained by dissolving $\mathrm{Pb}\left(\mathrm{NO}_{3}\right)_{2}$ and $\mathrm{CdCl}_{2}$. After adsorption in the $\mathrm{pH}$ range from 1 to 6 , the concentrations of remaining metals in the solutions were measured by an inductively coupled plasma mass spectroscopy (ICP-MS). In the column mode, 0.05g of adsorbent was packed into the column, $7 \mathrm{~mm}$ in inner diameter. The height of the adsorbent was $1.0 \mathrm{~cm}$ in the column. Then, $10 \mathrm{mM}\left(\mathrm{M}=\mathrm{mol} \mathrm{dm}{ }^{-3}\right)$ of metal solution $(\mathrm{pH} \mathrm{5)}$ was pumped into the column with a peristaltic pump. The metal concentration in the outflow solution was monitored by ICP-MS, also.

\section{Results and Discussion}

\subsection{Effect of solvent and reaction time}

The effect of solvent compositions on $D_{g}$ was investigated in the mixture of methanol and water. First, the grafting was carried out for 24 hours at $50^{\circ} \mathrm{C}$ in $20 \% \mathrm{HMPA}$ aqua solution. Many nodules of homopolymer were observed on the trunk polymer though the $D_{g}$ reached $190 \%$. Fig. 3 shows the effect of methanol component in water on $D_{g}$. The addition of $10 \%$ methanol to water was effective on prohibition of nodule production and the $D_{g}$ was still $186 \%$. Further increase of methanol composition monotonously reduced the $D_{\mathrm{g}}$. In the methanol composition of $50 \%$ and $90 \%$, the<smiles>C=C(C)C(=C)C(=O)OCCOP(=O)(O)OCCOP(=O)(O)OCCOC(=O)C(=C)C</smiles>

Fig. 1 Components of phosphoric acid monomer and their chemical structures

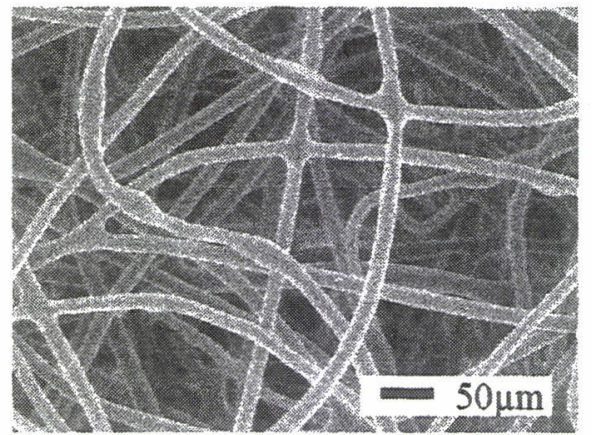

Fig. 2 SEM observation of trunk polymer (nonwoven fabric)

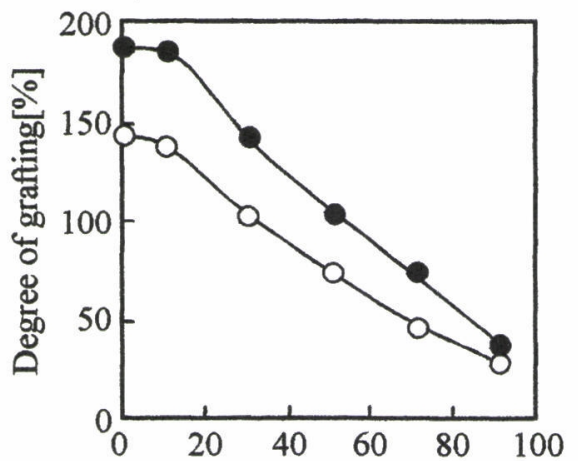

Methanol component in water [\%]

Fig. 3 Effect of solvent composition on degree of grafting; $(\mathrm{O}) 12 \mathrm{~h}$ grafting and (•) $24 \mathrm{~h}$ grafting 


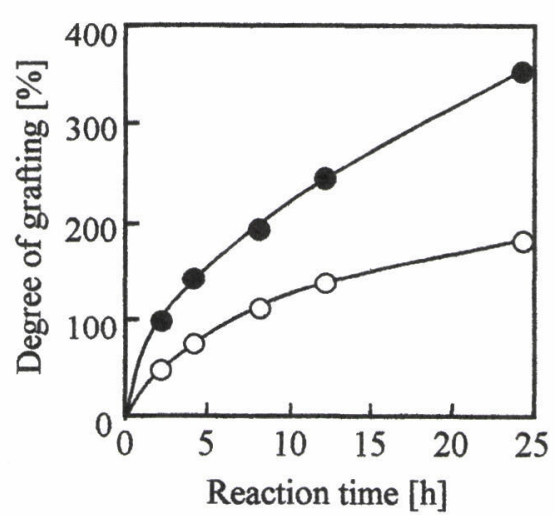

Fig. 4 Effect of reaction time on $D_{g}$; (•) $20 \%$ monomer and (O) $10 \%$ monomer.

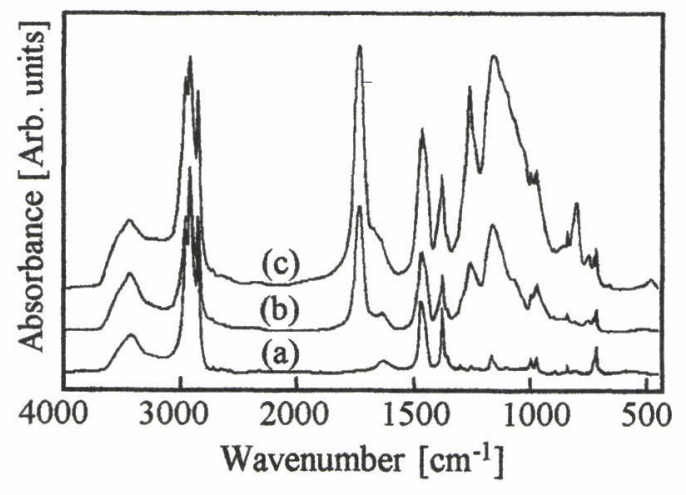

Fig. 5 IR spectra of trunk polymer and grafted polymers; (a) trunk polymer (b) $56 \% D_{g}$ and (c) $106 \% D_{g}$

degrees of grafting became $105 \%$ and $40 \%$, respectively.

Figure 4 shows the effect of grafting time on $D_{g}$ at reaction temperature of $60^{\circ} \mathrm{C}$ by using 10 and $20 \%$ of HMPA in the mixture of $10 \%$ methanol and $90 \%$ water. The $D_{g}$ increased with increment of the reaction time. After 24 h reaction, the $D_{g}$ reached 185 and $354 \%$ for 10 and 20\% of HMPA concentration. As a result, the increase of the monomer concentration from 10 to $20 \%$ gave 2 times higher $D_{g}$. The rise of reaction temperature is effectve on the increase of $D_{g}$. The rise from 50 to $60^{\circ} \mathrm{C}$ doubled the $D_{g}$.

\subsection{Characterization of adsorbent}

The introduction of HMPA on the trunk polymer was evaluated by IR spectroscopy. Fig. 5 shows the spectra of $\mathrm{KBr}$ compressed disk containing the milled nonwoven fabric and the grafted one. In the spectrum of $56 \% D_{g}$, the absorption peaks appeared at 1732,1262 , and $1151 \mathrm{~cm}^{-1}$ on the spectrum of the trunk polymer. The peaks of 1732,1262 , and $1151 \mathrm{~cm}^{-1}$ were attributed to $\mathrm{C}=\mathrm{O}, \mathrm{P}=\mathrm{O}$, and O-P-O bonds of HMPA, respectively. When the $D_{g}$ was $106 \%$, the corresponding three peaks to HMPA increased proportionally.

The trunk polymer and grafted one were observed with scanning electron microscope to compare their fiber diameter. The average diameters of fiber in the trunk polymer, $D_{g}$ of 100,200 , and $300 \%$ were $13,15,16$ and $17 \mu \mathrm{m}$, respectively. Fig. 6 shows the observation of the enlarged trunk polymer and $300 \% D_{g}$ polymer. The both fiber surfaces were smooth and there were little considerable damages by grafting. These results imply the grafting HPMA up to around $300 \% D_{g}$ were possible without any physical damages on the nonwoven fabric. Fig. 7 shows the cross-section areas which were calculated from their diameter were plotted against the $D_{g}$. There is a linear relationship between the cross-section area and $D_{g}$.

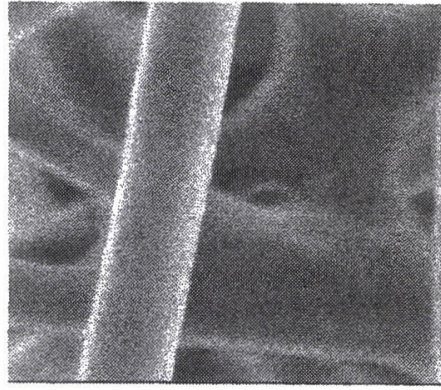

(a)

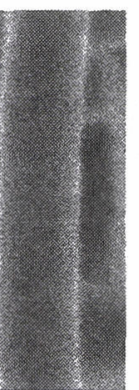

$20 \mu \mathrm{m}$

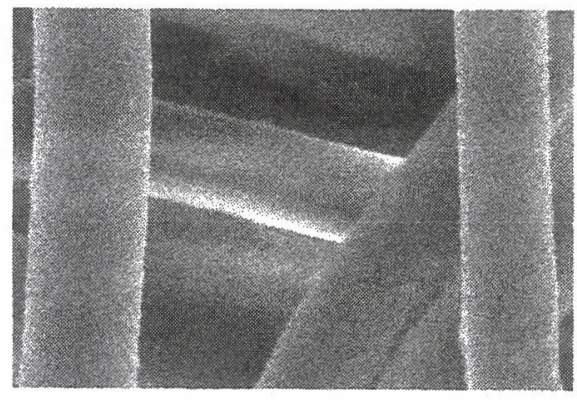

(b)

Fig. 6 SEM photographs of (a) trunk polymer and (b) grafted polymer of $300 \% \mathrm{Dg}$. 


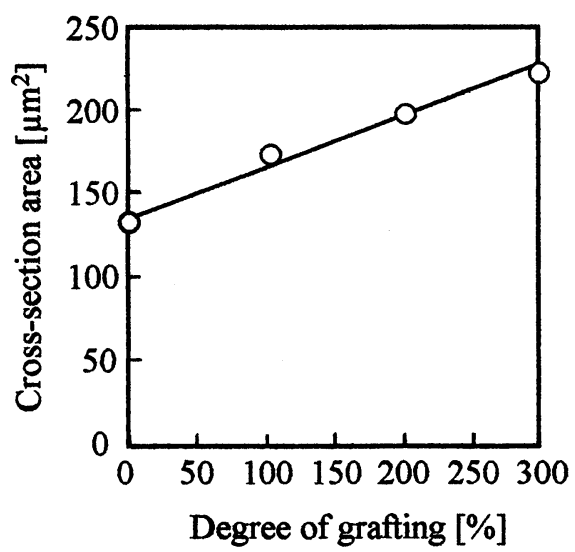

Fig. 7 Relationship between $D_{g}$ and cross-section area

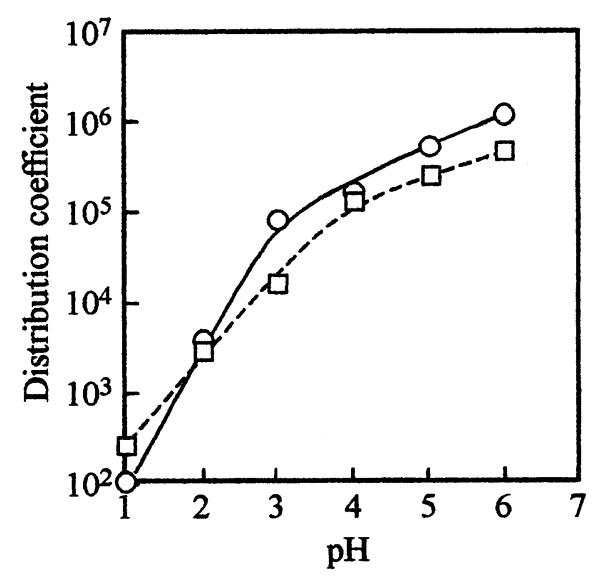

Fig. 8 Effect of $\mathrm{pH}$ on distribution coefficients; $(\mathrm{O}) \mathrm{Pb}$ and $(\square) \mathrm{Cd}$

\subsection{Batch adsorption}

Effect of $\mathrm{pH}$ on metal adsorption was investigated at $\mathrm{pH}$ range from 1 to 6 by using $10 \mathrm{ppm}$ of $\mathrm{Pb}$ and $\mathrm{Cd}$ solutions. The highest performance on the adsorption was obtained at $\mathrm{pH} 6$ for these two metals. After contact with $10 \mathrm{ppm}$ metal solution for $48 \mathrm{~h}, 99.6 \%$ of $\mathrm{Pb}$ and $99.0 \%$ of $\mathrm{Cd}$ were caught on the phosphoric adsorbents. The distribution coefficient of each metal was calculated by dividing the concentration in the solution with that on the adsorbent as shown in Fig. 8. The obtained distribution coefficients for $\mathrm{Pb}$ and $\mathrm{Cd}$ were $1.2 \times 10^{6}$ and $4.9 \times 10^{5}$ at pH 6. The adsorbent had excellent ability without any significant loss of adsorption capacity after the adsorption-desorption was repeated 5 times.

\subsection{Column adsorption}

Column mode adsorption was carried out by using the $10 \mathrm{mM}$ solutions of $\mathrm{Pb}$ and $\mathrm{Cd}$ with the space velocity of $250 \mathrm{~h}^{-1}$. The characteristic of breakthrough was observed by plotting $\mathrm{C} / \mathrm{C}_{0}$ which was the value of outflow concentration divided by the injecting concentration against bed volume as shown in Fig. 9. When the breakthrough points were determined at $\mathrm{C} / \mathrm{C}_{0}$ of 0.1 , the breakthrough capacities were 23 and 25 bed volume for $\mathrm{Pb}$ and $\mathrm{Cd}$, respectively. These values correspond to 1.8 and $2.0 \mathrm{mmol} / \mathrm{g}$-adsorbent. After breakthrough point, the value of $\mathrm{C} / \mathrm{Co}$ went up 0.9 quickly. The total capacities of adsorption were 2.8 and $3.0 \mathrm{mmol} / \mathrm{g}$-adsorbent for $\mathrm{Pb}$ and $\mathrm{Cd}$, respectively.

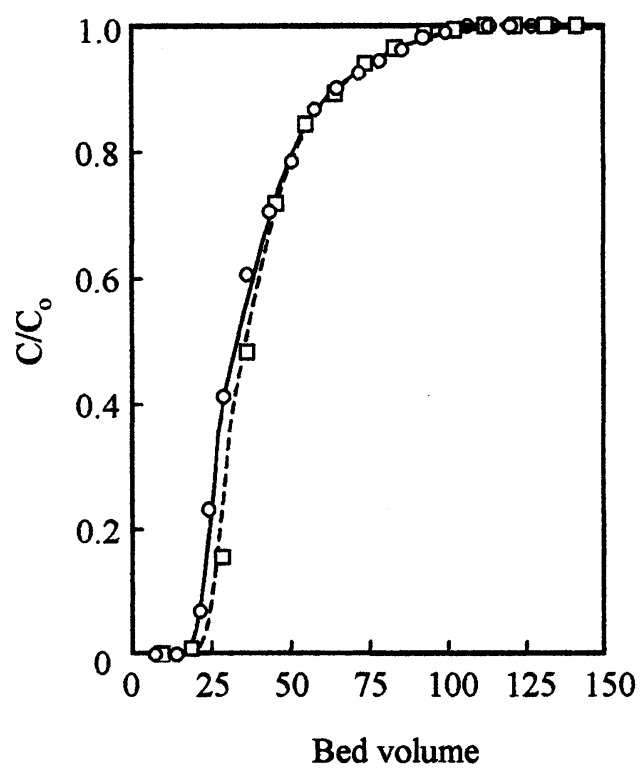

Fig. 9 Column mode of adsorption; (O) $\mathrm{Pb}$ and (口) $\mathrm{Cd}$

\section{References}

1) A. Jyo, S. Akoki, T. Kishida, K. Yamabe, M. Tamada, and T. Sugo, Anal. Sci, 17 supplemet, i201-i204 (2001).

2) S. D. Smith and S. D. Alexandratos, Solv. Extr. Ion Exch. 18, 779-807 (2000).

3) K. Park, C. Chang, H. Kim, S. Choi, and Y. Nho, Anal. Sci. Technol. 12, 7-12 (1999).

4) S. Mosleh, J. Appl. Polym. Sci., 77, 1357-1361 (2000). 